\title{
RECIST criteria: our experience in daily practice
}

\author{
S De Luca*, C Carrera, E Casalini Vañek, L Tolkachier, L Alarcon, E Eyheremendy \\ From International Cancer Imaging Society Meeting and 15th Annual Teaching Course (ICIS 2015) \\ London, UK. 5-7 October 2015
}

\section{Learning objectives}

Describe the utility and limitations of RECIST 1.1 criteria.

Emphasise the knowledge of complementary tools for the evaluation of response to treatment of solid tumours.

\section{Content organisation}

Our cases will be presented in a pictorial essay mode. Key differential diagnostic points will be highlighted in the discussion of each case.

It is important to consider:

Complete knowledge of clinical-oncologic status and treatments time points.

Recognition of smallest measured value (NADIR) between time points for adequate selection of comparative review.

Sum of target lesions (baseline and current time points) including percentage of change.

Select no more than two target lesions by sector.

Complete knowledge of actinic extension field which often could present different behavior than other lesional sites.

Local tumour growth over vital organs regardless strict RECIST criteria in exceptional cases.

Further criteria utilization in line with oncological disease being studied (mRECIST criteria for hepatocellular carcinoma or CHOI criteria for GIST).

Use of SUL on baseline PET CT studies with greater accuracy in assessing response on further evaluations (PERCIST criteria).

\section{Conclusion}

RECIST 1.1 proposes internationally accepted criteria to unify and standardise response to treatment of solid tumours in oncologic patients.

These criteria are reproducible but in some oncologic scenarios, we need to widen its use, due to the large

\footnotetext{
* Correspondence: sdeluca@hospitalaleman.com
} Hospital Aleman, Buenos Aires, Argentina

(c) 2015 De Luca et al. This is an Open Access article distributed under the terms of the Creative Commons Attribution License (http:// creativecommons.org/licenses/by/4.0), which permits unrestricted use, distribution, and reproduction in any medium, provided the original work is properly cited. The Creative Commons Public Domain Dedication waiver (http://creativecommons.org/publicdomain/ zero/1.0/) applies to the data made available in this article, unless otherwise stated. 